\title{
Study of the Potential Application of Lactic Acid Bacteria in the Control of Infection Caused by Agrobacterium tumefaciens
}

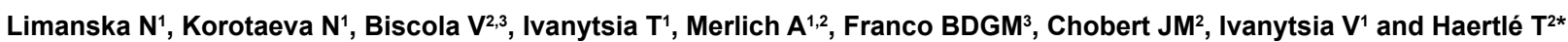

${ }^{1}$ Microbiology, Virology and Biotechnology Chair, Biological Department, Odessa National I.I. Mechnikov University (ONU), 65082 Dvoryanska str., 2, Odessa, Ukraine ${ }^{2}$ UR 1268 INRA Biopolymères Interactions Assemblages, BP 71627, rue de la Géraudière, 44316 Nantes Cedex 3, France

${ }^{3}$ Department of Food and Experimental Nutrition, Faculty of Pharmaceutical Sciences, University of São Paulo, 580, Professor Lineu Prestes, 13 B, Sao Paulo, SP, 05508000, Brazil

\begin{abstract}
Inhibition of crown gall on test plants in case of co-inoculation with lactic acid bacteria (LAB) has been investigated. From nine LAB strains tested, eight reduced amount of galled carrot explants by $36.4-87.7 \%$ and decreased the intensity of disease manifestation. The antagonistic activity against Agrobacterium tumefaciens, in vitro, was due to the low $\mathrm{pH}$ of organic acids produced by LAB. However, in the same $\mathrm{pH}$, different LAB cultures displayed various levels of inhibition in vivo. Lactobacillus plantarum ONU 12 with the best results in tumor inhibition on carrots, showed high antagonistic activity on surfaces of kalanchoe and grapevines. Depending on the method of inoculation, the culture of $L$. plantarum ONU 12 could protect from $72.7 \%$ to $100 \%$ of wounded kalanchoe tissues. Evaluation of number of surviving cuttings and amount of buds that grew indicated that co-inoculation with agrobacteria and LAB removed completely the negative influence of phytopathogen on grapevines and reduced the number of infected cuttings by approximately $80 \%$. One-hour treatment with L. plantarum ONU 12 helped to decrease the number of infected plants by approximately $68 \%$. The studied strain L. plantarum ONU 12 can be proposed for further evaluation of possibility of practical use in plant protection.
\end{abstract}

Keywords: Antagonism; Crown gall; Lactobacillus; Enterococcus

\section{Introduction}

Lactic acid bacteria (LAB) are widely used in many fields of human activity and especially in food preservation and in medicine. Some authors have proposed to apply lactobacilli for improvement of crop plant yields and for protection of agriculturally important species against certain phytopathogens. Visser et al. [1] reported antagonistic action of Lactobacillus plantarum L292 against Pseudomonas syringae observed in vivo on haricot beans resulting in significant reduction of disease symptoms. Inhibition of Xanthomonas campestris growth with L. plantarum strains was described by Trias et al. [2] and Dalirsaber Jalali et al. [3]. Other LAB such as Enterococcus mundtii suppressed the growth of Erwinia carotovora. Bacterial mixtures containing mostly lactobacilli were efficient against Ralstonia solanacearum [4].

Recent publications described also the antimycotic effects of LAB. These effects are often species- and strain-specific. For instance, certain strains of Weissella cibaria, L. plantarum, Leuconostoc mesenteroides and Lactococcus lactis reduced rot caused by Penicillium expansum in wounds of stored apples while other tested strains did not exhibit such activities [2]. El-Mabrok et al. [5] reported the inhibition of phytopathogenic fungi Colletotrichum gloeosporioides by strains of $L$. plantarum. Lactobacilli were used for decreasing disease symptoms or production of metabolites responsible for food intoxication caused by Fusarium [6], Aspergillus flavus [7], Aspergillus ochraceus [8], Aspergillus niger and Penicillium expansum [9].

The main metabolites from $\mathrm{LAB}$ found to be active against phytopathogens were organic acids and hydrogen peroxide; the microbial competition was also described $[2,7,10]$.

Interesting results of aforementioned authors stimulated to study the possibilities of use of LAB against known phytopathogen Agrobacterium tumefaciens (Rhizobium radiobacter according to the nomenclature proposed by Young et al. [11], which can be devastating for the nurseries of stone fruits and ornamental plants. The symptoms of the caused disease (crown gall) are tumor formations on stems and roots of infected plants resulting in deficiency of nutrients and water supply (reviewed in Burr and Otten, [12]). Tissue proliferations induced by pathogenic agrobacteria also include cane gall caused by $A$. rubi (R.rubi) and hairy-root as the result of infection with $A$. rhizogenes ( $R$. rhizogenes) [11,13]. Strains of $A$. tumefaciens biotype 3 were reclassified as a distinct species $A$. vitis (R. vitis) on the basis of their host (Vitis spp.) and their genetic peculiarities [11,14]. Besides by A. vitis, crown gall on grapevine in some cases can be caused by $A$. tumefaciens biotype 1 strains $[15,16]$.

The pathogenesis of crown gall is unique and includes the transfer of the part of Ti-plasmid from A. tumefaciens into the chromosome of the plant [17]. As the result, plant cells start to produce an increased amount of hormones leading to uncontrolled tissue proliferation [18] and to synthesize the unusual compounds such as are opines - derivatives of sugars and special amino acids used by bacteria as nutritional sources $[19,20]$.

Representatives of several bacterial genera have been used for efficient biocontrol of crown gall. Some avirulent agrobacteria produce highly specific bacteriocin agrocin as A. rhizogenes K84 does - the

*Corresponding author: Thomas Haertlé, UR 1268 INRA Biopolymères Interactions Assemblages, BP 71627, rue de la Géraudière, 44316 Nantes Cedex 3, France, Tel: 33240675091; Fax: 33240675244; E-mail: haertle@nantes.inra.fr

Received July 31, 2015; Accepted August 13, 2015; Published August 20, 2015 Citation: Limanska N, Korotaeva N, Biscola V, Ivanytsia T, Merlich A, et al (2015) Study of the Potential Application of Lactic Acid Bacteria in the Control of Infection Caused by Agrobacterium tumefaciens. J Plant Pathol Microb 6: 292 doi:10.4172/2157-7471.1000292

Copyright: (c) 2015 Limanska N, et al. This is an open-access article distributed under the terms of the Creative Commons Attribution License, which permits unrestricted use, distribution, and reproduction in any medium, provided the original author and source are credited. 
most widely used antagonistic strain against A. tumefaciens [21]. The genes responsible for agrocin synthesis and self-immunity are localized on a plasmid, which can be transferred into pathogenic strains and make them resistant [22]. To overcome biocontrol failure, a stable Tra deletion mutant of K84 - the strain K1026 was constructed [23]. Biopreparations based on K84 have been traditionally used for many years $[20,24]$. Being highly effective in many dicotyledonous plants, $A$. rhizogenes $\mathrm{K} 84$ does not affect crown gall agents in grapevines [25]. One of the most active antagonists decreasing level of tumour formation in grape is $A$. vitis F2/5 [26-28]. Its inhibitory effect cannot be explained by agrocin production and competition for attachment sites but it is directly related to interactions with grapevine cells resulting in cambium necroses resembling hypersensitivity response [29-31]. A. vitis $\mathrm{F} 2 / 5$ does not affect the growth of pathogen population in plant tissue but inhibits the tissue transformation [32].

Several other efficient antagonists strains belonging to species A. vitis are known. A. vitis E26 effectively inhibited crown gall on peach and cherry caused by $A$. tumefaciens and on grapevine caused by $A$. vitis [33]. The antagonistic effect was explained by bacteriocin production $[34,35]$.

A. radiobacter HLB-2 supressed grape crown gall by bacteriocin production and competing for attachment sites and nutrients [36,37]. A. vitis VAR03-1 has shown a significant reduction effect of gall formation in tomatoes, roses and grapevines [38,39]. Recently described novel antagonistic strain A. vitis ARK-1 reduced the tumor incidence in grapevine plants and stably survived on roots [40].

The other important antagonists against crown gall agents belong to Pseudomonas genus. Crown gall formation on grapevine and raspberry was efficiently inhibited with $P$. aureofaciens and $P$. fluorescens $[41,42]$. The similar clear antagonistic activity was revealed in $P$. corrugate isolated from grapevine xylem sap. Besides this bacterium, the inhibitory effect against $A$. vitis was demonstrated by strains of Enterobacter agglomerans and Rahnella aquatilis isolated from the same source [43]. It was revealed also that a specific antimicrobial compound with wide spectrum of action was responsible for the suppressive effect of Rahnella aquatilis [44]. Treatments with Pseudomonas putida, Burkholderia phytofirmans and Azospirillum brazilense strains producing 1-aminocyclopropane-1-carboxylate deaminase, which degrades the precursor of ethylene in plants, inhibited the tumor formation in tomatoes [45].

Bacilli also have been investigated as possible biocontrol agents against crown gall. Bacillus subtilis and Bacillus spp. reduced gall size in treated plants and densities of internal populations of $R$. vitis [42]. A biopreparation based on B. subtilis could significantly reduce disease incidence. Additional use of resistance inducers for plants was strongly recommended to decrease crown gall severity under the field conditions [46].

Trials of using LAB against $A$. tumefaciens described in literature have not been found, although this trend of biological control in plant protection is very attractive because of some important characteristics of these agents, such as their capability of inhibiting other microorganisms by competition and production of antimicrobial compounds such as organic acids and bacteriocins. Besides some LAB, such as Lactobacillus plantarum, are considered by the Food and Agriculture Organization (FAO) as GRAS (Generally Recognized As Safe) for the application in biopreservation systems.

Hence, the aim of this work was to test in vivo the antagonistic activity of some LAB strains isolated from various sources against $A$. tumefaciens.

\section{Materials and Methods}

\section{Bacterial strains}

The tested LAB strains originated from the collection of cultures of Microbiology, Virology and Biotechnology Chair of ONU, Odessa, Ukraine and from the collection of BIA-FIP laboratory, INRA, Nantes, France (Dr. S. Migaw and Dr. M. Barbosa). Pathogenic strain A. tumefaciens C58 was kindly provided by the collection of microorganisms of D.K. Zabolotny Institute of Microbiology and Virology (Dr. F.I. Tovkach), Kiev, Ukraine. All LAB strains were stored in MRS broth [47] and A. tumefaciens C58 in Luria Bertani (LB) broth [48] at $-80^{\circ} \mathrm{C}$ with $20 \%$ glycerol. Strains L. plantarum ONU 87 , ONU 206 and ONU 991 were isolated from dairy products and L. plantarum ONU 12, ONU 311, ONU 312, ONU 313 from grape berries collected in Ukraine; Enterococcus faecium C8 was isolated from Azerbaijan cheese, and Enterococcus durans $3 y$ from Tunisian fish.

\section{Inoculation of carrot explants}

Carrots (Daucus carota L.) were purchased on local markets of France and Ukraine, washed with commercial "Javel" (sodium hypochlorite) solution, rinsed in tap water, immersed in ethanol, flamed, peeled and sliced in discs [49]. The disks were placed in sterile Petri dishes. A. tumefaciens was cultivated overnight in LB broth at $28^{\circ} \mathrm{C}$, and the final concentration of cells reached up 2-8 $\mathrm{x}$ $10^{9} \mathrm{CFU} / \mathrm{mL}$. LAB cell suspensions were obtained by inoculation of each strain in MRS broth followed by incubation overnight at $37^{\circ} \mathrm{C}$ (final concentration $1-5 \times 10^{10} \mathrm{CFU} / \mathrm{mL}$ ). The inoculum was obtained by mixing the culture of $A$. tumefaciens with the LAB cultures in equal volumes (1/1). To inoculate the carrots, $100 \mu \mathrm{L}$ of the mixture were applied on the basal surfaces of the disks. Besides mixtures " $A$. tumefaciens C58/LAB", agrobacterial culture mixed with sterile saline solution $(0.85 \% \mathrm{NaCl}, \mathrm{w} / \mathrm{v})$ at a ratio $1: 1$ was applied on explants as a positive control, and LAB cultures - as negative controls. After 21 days, explants were observed for the presence of tumors and fermentation. Amount of galled explants was calculated and manifestation of crown gall symptoms was evaluated by the modified method of Ryder et al. [48] as follows: " ++++ " $100 \%$ cambial ring covered with tumors; "+++" $75 \%$ of cambial ring with tumors; " $++" 50 \%$ of cambial ring with tumors; "+" less than $25 \%$ of cambial ring with tumors.

\section{Production of antimicrobial metabolites}

Cell Free Supernatant (CFS) instead of bacterial cultures was applied on carrot explants together with agrobacteria. LAB strains with the best results in the previous experiments (L. plantarum ONU 311, L. plantarum ONU 312, L. plantarum ONU 12, E. faecium C8 and E. durans 3y) were used. To obtain the CFS, LAB were grown in MRS broth at $37^{\circ} \mathrm{C}$ for $24 \mathrm{~h}$, and cells were harvested by centrifugation $(8000$ g, $4^{\circ} \mathrm{C}, 10 \mathrm{~min}$ ).

The production of antimicrobial compounds was also evaluated in vitro by agar-well diffusion assay according to Batdorj et al. [49] using CFS of the same LAB strains applied in the in vivo tests. CFS was obtained after incubation of LAB at $30^{\circ} \mathrm{C}$ and $37^{\circ} \mathrm{C}$ for $24 \mathrm{~h}$ in MRS broth. For the agar-well diffusion test, Brain Heart Infusion (BHI) soft agar $(0.8 \%, \mathrm{w} / \mathrm{v})$ or LB soft agar $(0.8 \%$ agar, w/v) were inoculated with $10^{6} \mathrm{CFU} / \mathrm{mL}$ of the indicator strain, L. ivanovii ATCC 19119 (as a classic test strain for the study of LAB bacteriocinogenic activity) or A. tumefaciens C58, respectively. The concentrations of bacterial 
cultures were assesed spectrophotometrically and serial dilutions were carried out to obtain the needed concentrations of cells. $50 \mu \mathrm{L}$ of CFS with initial acidic $\mathrm{pH}$ and $\mathrm{pH}$ adjusted to neutral with $1 \mathrm{~N} \mathrm{NaOH}$ were poured into wells made on the surface of the plates containing each indicator strain. After $24 \mathrm{~h}$ of incubation at $37^{\circ} \mathrm{C}$ for L. ivanovii ATCC 19119 or at $28^{\circ} \mathrm{C}$ for $A$. tumefaciens, the presence of inhibition zones was observed [50].

Co-incubation of agrobacteria in a mixture with LAB suspensions with different initial $\mathrm{pH}$ (4.1-4.5 and 5.0-5.5) during one hour was carried out at $28^{\circ} \mathrm{C}$. After the incubation period, bacterial mixtures were diluted ten-fold, plated on LB medium, incubated overnight and colonies of agrobacteria were counted.

\section{Inoculation of Kalanchoe daigremontiana Mill}

Five methods of inoculation were applied. (1) $50 \mu \mathrm{l}$ of L. plantarum ONU 12 overnight culture were injected together with $50 \mu \mathrm{l}$ of agrobacterial overnight culture into upper tissues of leaves by sterile syringe. Agrobacterium tumefaciens culture with equivalent volumes of sterile distillated water (SDW) were injected as positive controls. The culture of lactobacilli was applied as a negative control. (2) $100 \mu \mathrm{l}$ of a mixture "A. tumefaciens C58/L. plantarum ONU 12" were spotted on one-cm wounds made on leaves. (3) Wounds were treated with agrobacteria and after 30 min with L. plantarum ONU 12 culture. (4) Scars on leaves were treated with LAB and after $30 \mathrm{~min}$ inoculated with the phytopathogen. (5) Roots and the aerial parts (crowns) of plants were wounded and dipped for one hour in agrobacterial culture (positive control), SDW, culture of L. plantarum ONU 12 (negative controls) and in the mixture "C58/ONU 12". Plants were cultivated under greenhouse conditions. Leaves were observed for crown gall symptoms on the $60^{\text {th }}$ day after inoculation. Treated roots and crowns were observed after six months. Tumor tissues were excised and weighted.

\section{Inoculation of grapevine cuttings}

Cuttings of Vitis vinifera L. cv. Pinot noir, Vostorg, Moldova (in equal quantities each) cultivated in the south of Ukraine were gathered during March of 2011-2013. Cuttings with freshly cut basal parts soaked for one hour in agrobacterial culture were used as positive controls. Cuttings were also treated for one hour with L. plantarum ONU 12 culture and with the mixture "C58/ONU 12". One variant of the treatments was soaking for one hour in L. plantarum ONU 12 culture and after inoculation with A. tumefaciens C58 culture for 15 $\min$.

As negative controls, cuttings soaked for one hour in tap water were brought to assay. Other negative controls were MRS ( $\mathrm{pH} 4.1$ ) and a mixture "MRS/LB" (1:1) with $\mathrm{pH}$ 5.5-6.0 indicating the effect of nutritional media with $\mathrm{pH}$ of subsequent bacterial cultures on grape cutting development.

Cuttings were planted in commercial pot soil with abundance of peat and cultivated under greenhouse conditions for 30 days. After, amount of surviving cuttings and number of buds that grew were evaluated as percentages from the total quantity of tested cuttings and buds. Green shoots on survived cuttings were measured, and mean lengths were calculated in each variant. Cuttings were tested for the presence of pathogens by a bacterial culture method followed by polymerase chain reaction (PCR) assay with the primers to ipt oncogene of pathogenic agrobacteria according to Haas et al. [51].

\section{Statistical analyses}

Carrots were inoculated in three independent experiments with 20-22 explants in each variant for bacterial cultures and CFS. For kalanchoe inoculation, a total of 90 plants of each variant was used in three independent experiments. 30-50 grape cuttings were treated in each variant in three independent experiments carried out during springs of 2011-2013. Agar-well diffusion assay was carried out in five repeats for each variant. $\mathrm{CFU} / \mathrm{mL}$ in bacterial suspensions were evaluated by counting colonies grown in five repeats. The obtained results were presented in percentages and standard errors (SE) for qualitative attributes (number of infected plants and explants with necroses, amount of buds that grew) and in mean values with $95 \%$ confidence intervals (CI) for quantitative attributes (lengths of green shoots, amount of $\mathrm{CFU} / \mathrm{mL}$ ). Significant differences between the control and test samples were estimated in $t$-test $(\mathrm{p}<0.05)$ and marked in the tables with data. Software "Microsoft Excel" was used for calculations and graphics.

\section{Results}

\section{Tests on carrot explants}

The best results for tumor growth inhibition on carrot discs coinoculated with A. tumefaciens C58 and LAB cultures were obtained with 5 strains from 9 tested. L. plantarum ONU 12, E. faecium C8, L. plantarum ONU 312, E. durans 3y and L. plantarum ONU 311 suppressed completely tumor development on the majority of carrot discs, suggesting a high antagonistic activity of the mentioned lactobacilli and enterococci (Table 1).

The reduction in galled samples was observed in case of all tested LAB strains except $L$. plantarum ONU 991 (Figure 1).

The obtained results suggest that the antagonistic activity against $A$. tumefaciens within L. plantarum species is strain-specific.

Co-inoculation with LAB cultures shifted the level of crown gall manifestation to smaller area of galled tissue ("+" level compared with the positive control where “++" - “++++" levels were prevalent) (Table 2).

If after the treatments with active antagonistic strain $L$. plantarum ONU 12 some discs still appeared infected, less than $25 \%$ of cambial ring on disc were covered with tumors in such explants, while in case of non-active strain L. plantarum ONU 991 the range of tissue proliferation resembled that in the positive control.

The fermentation of carrot by some LAB strains occurred but it

\begin{tabular}{|c|c|c|c|}
\hline Inoculum & Percentage of discs with tumors & Inoculum & Percentage of discs with tumors \\
\hline A. tumefaciens C58 (positive control) & $61.0 \pm 6.0$ & A. tumefaciens C58 + L. plantarum ONU 311 & $16.4 \pm 4.7^{\mathrm{d}}$ \\
\hline A. tumefaciens C58 + L. plantarum 991 & $54.5 \pm 6.1$ & A. tumefaciens C58 + E. durans 3y & $13.6 \pm 4.2^{\mathrm{d}}$ \\
\hline A. tumefaciens C58 + L. plantarum ONU 313 & $38.8 \pm 5.9^{\mathrm{d}^{*}}$ & A. tumefaciens C58 + L. plantarum ONU 312 & $10.7 \pm 3.8^{d}$ \\
\hline A. tumefaciens C58 + L. plantarum ONU 206 & $30.0 \pm 5.9^{d}$ & A. tumefaciens $\mathrm{C} 58+$ E. faecium $\mathrm{C} 8$ & $9.1 \pm 3.5^{d}$ \\
\hline A. tumefaciens C58 + L. plantarum ONU 87 & $27.2 \pm 5.4^{\mathrm{d}}$ & A. tumefaciens C58 + L. plantarum ONU 12 & $7.5 \pm 3.2^{\mathrm{d}}$ \\
\hline
\end{tabular}

Note: ${ }^{\star d}$ - significant differences between values of the control and the test sample $(p<0.05, t$-test $)$

Table 1: Tumor formation on carrot explants after co-inoculation with A. tumefaciens C58 and LAB (\%). 
Citation: Limanska N, Korotaeva N, Biscola V, Ivanytsia T, Merlich A, et al. (2015) Study of the Potential Application of Lactic Acid Bacteria in the Control of Infection Caused by Agrobacterium tumefaciens. J Plant Pathol Microb 6: 292. doi:10.4172/2157-7471.1000292

Page 4 of 9

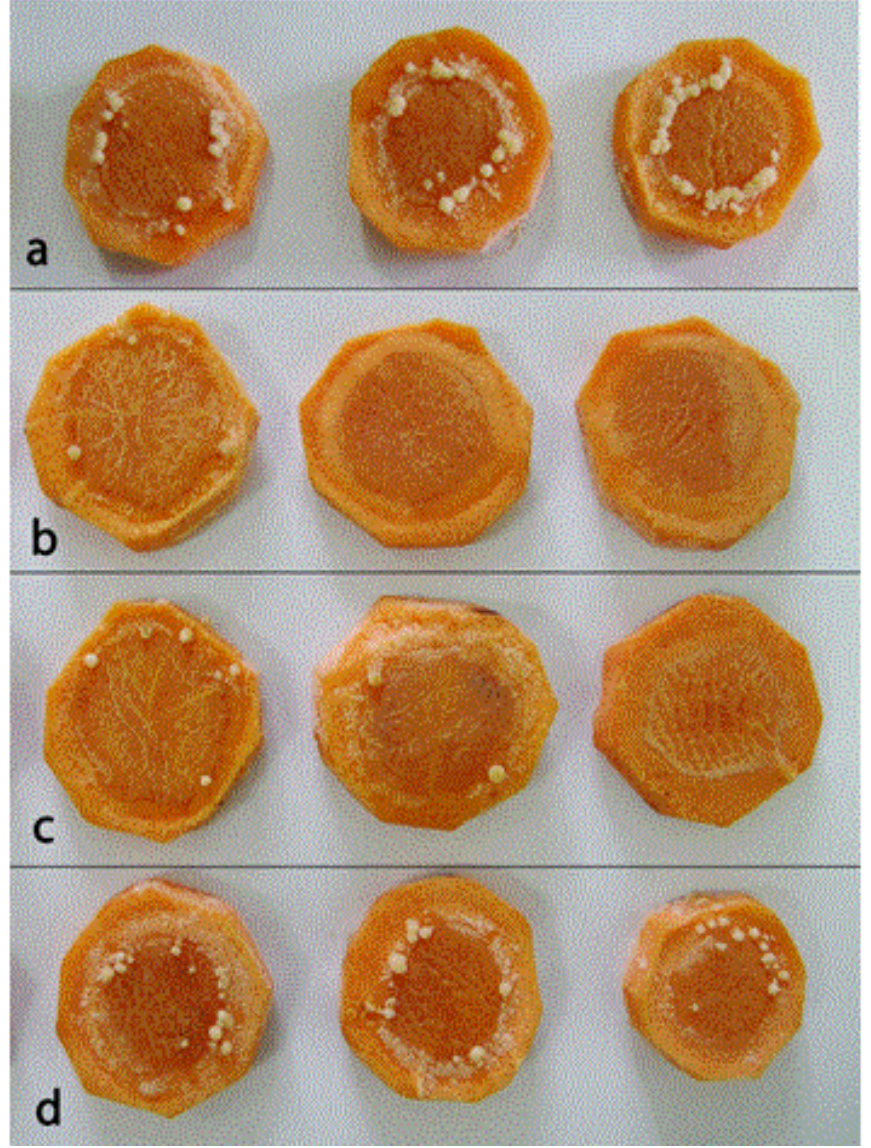

Figure 1: Carrot explants co-inoculated with various bacterial mixtures. a carrots inoculated only with $A$. tumefaciens C58 (positive control); b - carrots co-inoculated with A. tumefaciens C58 and L. plantarum ONU 12; c - carrots co-inoculated with $A$. tumefaciens $\mathrm{C} 58$ and $L$. plantarum ONU 312; $\mathrm{d}$ - carrots co-inoculated with A. tumefaciens C58 and L. plantarum ONU 991.

\begin{tabular}{|c|c|c|c|c|}
\hline Inoculum & + & ++ & +++ & ++++ \\
\hline A. tumefaciens C58 (positive control) & 30.0 & 40.0 & 20.0 & 10.0 \\
\hline A. tumefaciens C58 + L. plantarum 991 & 38.3 & 27.7 & 11.1 & 22.2 \\
\hline A. tumefaciens C58 + L. plantarum ONU 313 & 84.6 & 7.7 & 0 & 7.7 \\
\hline A. tumefaciens C58 + L. plantarum ONU 206 & 77.8 & 16.7 & 0 & 5.5 \\
\hline A. tumefaciens C58 + L. plantarum ONU 87 & 83.3 & 5.5 & 11.1 & 0 \\
\hline A. tumefaciens C58 + L. plantarum ONU 311 & 60.0 & 20.0 & 20.0 & 0 \\
\hline A. tumefaciens C58 + E. durans 3y & 55.5 & 22.2 & 11.1 & 11.1 \\
\hline A. tumefaciens C58 + L. plantarum ONU 312 & 85.7 & 14.3 & 0 & 0 \\
\hline A. tumefaciens C58 + E. faecium C8 & 66.6 & 33.3 & 0 & 0 \\
\hline A. tumefaciens C58 + L. plantarum ONU 12 & 100.0 & 0 & 0 & 0 \\
\hline
\end{tabular}

Table 2: Manifestation of crown gall symptoms on carrot discs in presence of LAB (\%).

did not attain more than $7.5 \pm 3.2 \%$ of discs (E. faecium C8) and 6.1 $\pm 2.9 \%$ (L. plantarum ONU 991), and was not detected in case of $L$. plantarum ONU 12, L. plantarum ONU 312, L. plantarum ONU 87 and $L$. plantarum ONU 206. Thus, number of fermented discs reached only $4.5 \pm 0.5 \%$ when $L$. plantarum ONU 313 was applied, $3.0 \pm 0.4$ in case of Enterococcus durans $3 y, 1.6 \pm 0.2 \%$ in case of L. plantarum ONU 311. Fermentative activity was less intense in case of the treatments of carrot explants with mixtures "Agrobacterium/LAB".

\section{Production of antimicrobial metabolites}

When CFS instead of cultures was applied, the results were similar to inoculation with alive LAB suspensions. Thus, treatments of explants with A. tumefaciens C58 in a mixture with CFS of L. plantarum ONU 12 caused crown gall symptoms only in $10.6 \pm 3.6 \%$ of explants, in case of $E$. faecium C8 CFS - in $8.3 \pm 4.8 \%$ of carrot discs, when treated with L. plantarum ONU 312 CFS - in $11.6 \pm 4.0 \%$, in case of E. durans $3 y$ CFS - in $15.0 \pm 4.6 \%$ of explants and in $18.3 \pm 4.9 \%$ of discs treated with CFS of L. plantarum ONU 311.

In case of the in vitro tests of production of antimicrobial compounds, it was observed that none of the strains was able to inhibit A. tumefaciens $\mathrm{C} 58$ when the CFS pH 6.5 was used. Otherwise, when the acidic CFS was applied into the agar wells, clear zones of inhibition were observed, suggesting that the activity against the phytopathogen was due to the production of organic acids. The $\mathrm{pH}$ of the acidic CFS obtained after cultivation of the selected $\mathrm{LAB}$ at $30^{\circ} \mathrm{C}$ or $37^{\circ} \mathrm{C}$ varied between 4.1 and 4.7 for lactobacilli and 4.7 and 5.0 for enterococci. Incubation of agrobacteria in a mixture with LAB suspension with initial $\mathrm{pH}$ 5.0-5.5 caused 1-2 fold decrease in viable pathogen cell quantity. If initial $\mathrm{pH}$ of $\mathrm{LAB}$ suspensions was 4.1-4.5, one-hour of coincubation was sufficient for 4 -folds decrease in amount of viable cells (Table 3).

The experiments carried out with L. ivanovii ATCC 19119 as indicator strain showed that the strains E. faecium $\mathrm{C} 8$ and $E$. durans $3 y$ inhibited its growth, when incubated at $30^{\circ} \mathrm{C}$ or $37^{\circ} \mathrm{C}$, suggesting the production of antimicrobial metabolites other than organic acids, such as bacteriocins. However, these metabolites were inactive against A. tumefaciens.

\section{Tests on Kalanchoe daigremontiana Mill}

Strain L. plantarum ONU 12 with the best result in crown gall inhibition on carrot explants was used for further investigations.

When the mixture of bacterial cultures "C58/ONU 12" was injected in kalanchoe leaf tissues, no tumors were formed in any of repeats (Figure 2).

Treatment of the scars with this mixture resulted in tumor formation just in one case that was evaluated as $1.1 \%$ from the total amount of infected plants.

If scars were first infected with A. tumefaciens C58 and after 30 min inoculated with LAB culture, the percentage of galled plants decreased in 3.5 times $(20.0 \pm 4.2 \%$ comparing with $73.3 \pm 4.6 \%$ in positive control) and mean weight of tumors was 4.4 times less $(0.0309 \pm 0.0181$ g comparing with $0.1325 \pm 0.0582 \mathrm{~g}$ in the positive controls).

Crown gall was not detected on the scars treated with LAB cultures 30 min before inoculation with the pathogen.

\begin{tabular}{|c|c|c|c|}
\hline \multirow{2}{*}{ Variant } & \multicolumn{3}{|c|}{ Amount of viable cells (CFU/mL) } \\
\cline { 3 - 4 } & \multirow{2}{*}{ Before incubation } & \multicolumn{2}{|c|}{ After incubation } \\
\cline { 3 - 4 } & & pH 5.0-5.5 & pH 4.1-4.5 \\
\hline C58 + ONU 311 & & $(4.2 \pm 0.7) \times 10^{7}$ & $(1.5 \pm 0.4) \times 10^{5}$ \\
\hline C58 + ONU 312 & \multirow{2}{*}{$(6.4 \pm 0.8) \times 10^{9}$} & $(2.2 \pm 0.5) \times 10^{7}$ & $(4.8 \pm 1.2) \times 10^{5}$ \\
\cline { 3 - 4 } C58 + ONU 12 & & $(1.6 \pm 0.3) \times 10^{7}$ & $(5.2 \pm 1.1) \times 10^{5}$ \\
\hline C58 + ONU 87 & & $(2.4 \pm 0.8) \times 10^{7}$ & $(2.1 \pm 0.2) \times 10^{5}$ \\
\hline
\end{tabular}

Table 3: Effect of $L A B$ on the survival of $A$. tumefaciens $C 58$ cells after one hour of co-incubation. 
Citation: Limanska N, Korotaeva N, Biscola V, Ivanytsia T, Merlich A, et al. (2015) Study of the Potential Application of Lactic Acid Bacteria in the Control of Infection Caused by Agrobacterium tumefaciens. J Plant Pathol Microb 6: 292. doi:10.4172/2157-7471.1000292
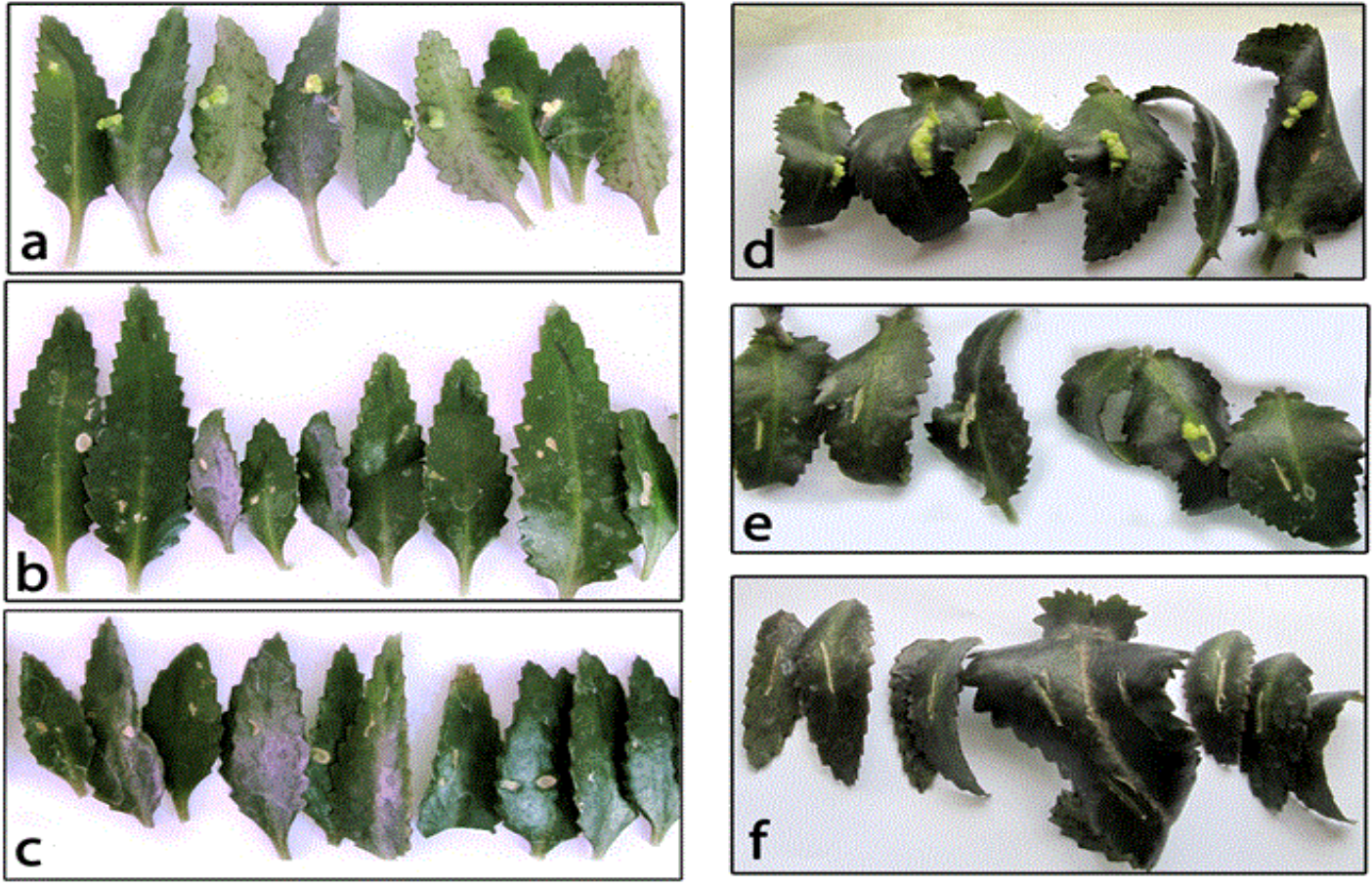

Figure 2: Kalanchoe leaves infected by injections (left) and by scars (right): a, d - inoculated only with A. tumefaciens C58; b, e - co-inoculated with A. tumefaciens C58 and L. plantarum ONU 12; c, f - inoculated with L. plantarum ONU 12.
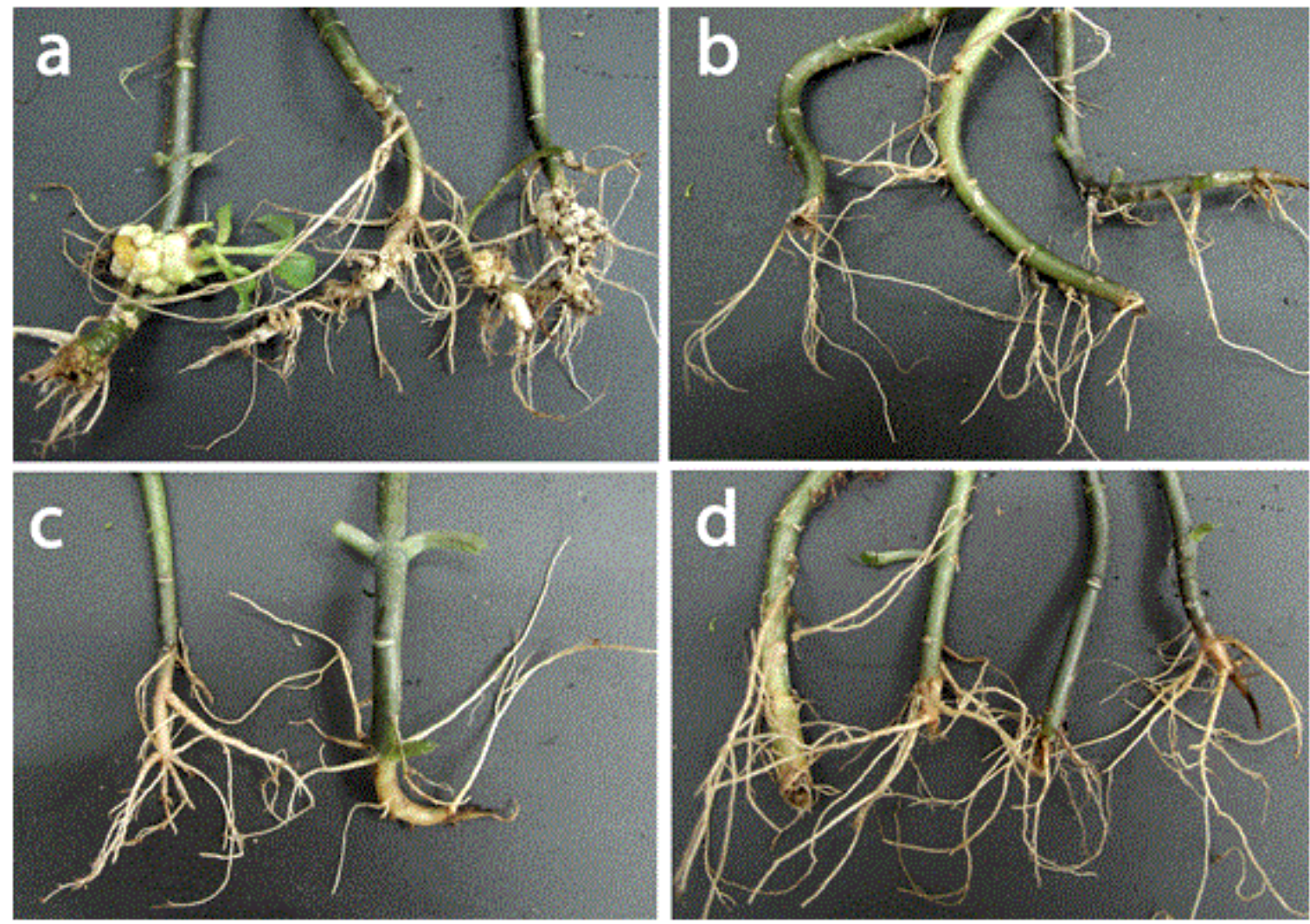

Figure 3: Kalanchoe plants infected via wounded crowns and roots: a - inoculated only with $A$. tumefaciens C58; b - co-inoculated with $A$. tumefaciens C58 and $L$. plantarum ONU 12; c - soaked in water; d - inoculated with L. plantarum ONU 12. 
After the treatments with a mixture "A. tumefaciens C58/L. plantarum ONU 12" and in some cases with LAB suspension, necroses were observed but they were restricted to wounded sites.

Treatment with LAB simultaneously with the inoculation with agrobacteria via root system allowed to protect plants in $100 \%$ of cases (Figure 3).

The obtained results indicated the high efficacy of using $L$. plantarum ONU 12 to inhibit crown gall on kalanchoe.

\section{Tests on grapevine cuttings}

Inoculation with A. tumefaciens $\mathrm{C} 58$ resulted in the induction of necroses on basal ends of $100 \%$ of the treated cuttings in positive controls. 24\% of inoculated cuttings died (Figure 4) and the surviving grapevines showed $9.4 \%$ smaller amount of buds that grew (Figure 5).

Inoculation with $L$. plantarum ONU 12 had a positive effect on the amount of buds that grew, but the effect was small (11.2\%). But the highest stimulating effect on buds that grew was revealed in case of the treatments with a mixture "A. tumefaciens C58/L. plantarum ONU 12". Soaking the cuttings in the mixture "A. tumefaciens C58/L. plantarum ONU 12 " during $1 \mathrm{~h}$ resulted in $45.0 \%$ increase in amount of buds that grew. One-hour treatments with LAB culture followed by subsequent inoculation with $A$. tumefaciens C58 during $15 \mathrm{~min}$ lead to $35.0 \%$ increase. The mixture of nutritional media MRS and LB in the same ratio as in the bacterial cultures did not demonstrate any stimulation of the treated cuttings.

When inoculation with A. tumefaciens C58 was carried out simultaneously with the treatment with $L$. plantarum ONU 12 culture, the negative effect of phytopathogen was not observed. All the evaluated characteristics of plants did not differ from that in the negative control (water). Thus, the number of surviving cuttings reached $85.3 \pm 3.5 \%$ in negative control, $64.8 \pm 5.6 \%$ in positive controls infected with pathogenic agrobacteria - and $89.7 \pm 5.0 \%$ in cuttings co-inoculated with A. tumefaciens C58 and L. plantarum ONU 12. Mean lengths

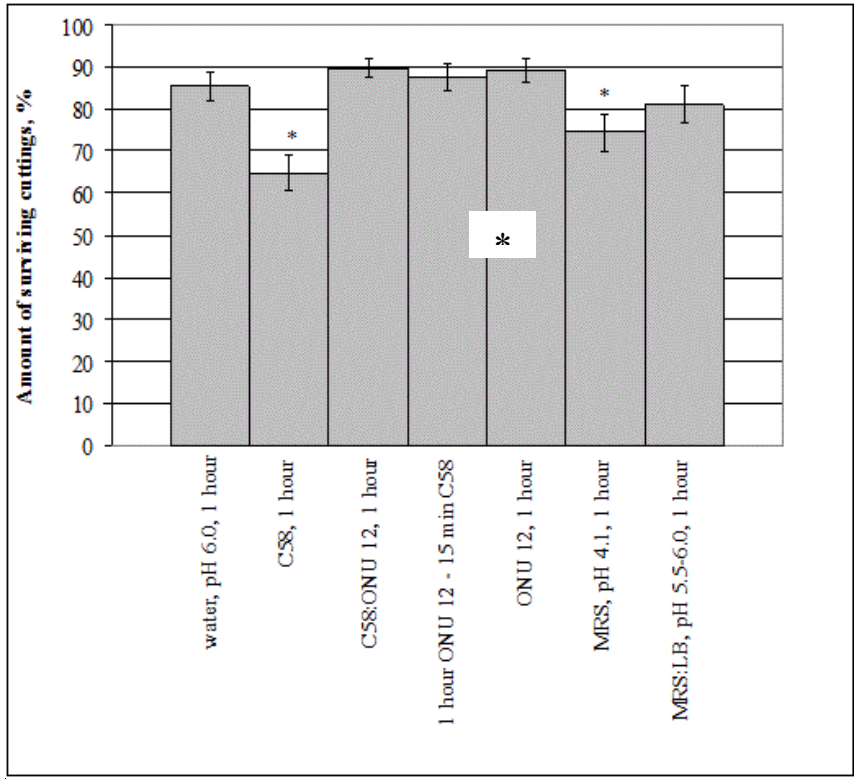

Figure 4: Survival of grape cuttings after the treatments with $A$. tumefaciens C58, controls and $L$. plantarum ONU 12 (expressed as a mean $\pm \mathrm{SE}$ ): * significant differences between means after soaking in SDW and soaking in agrobacteria and MRS medium with $\mathrm{pH} 4.1$ ( $\mathrm{p}<0.05, t$ test).

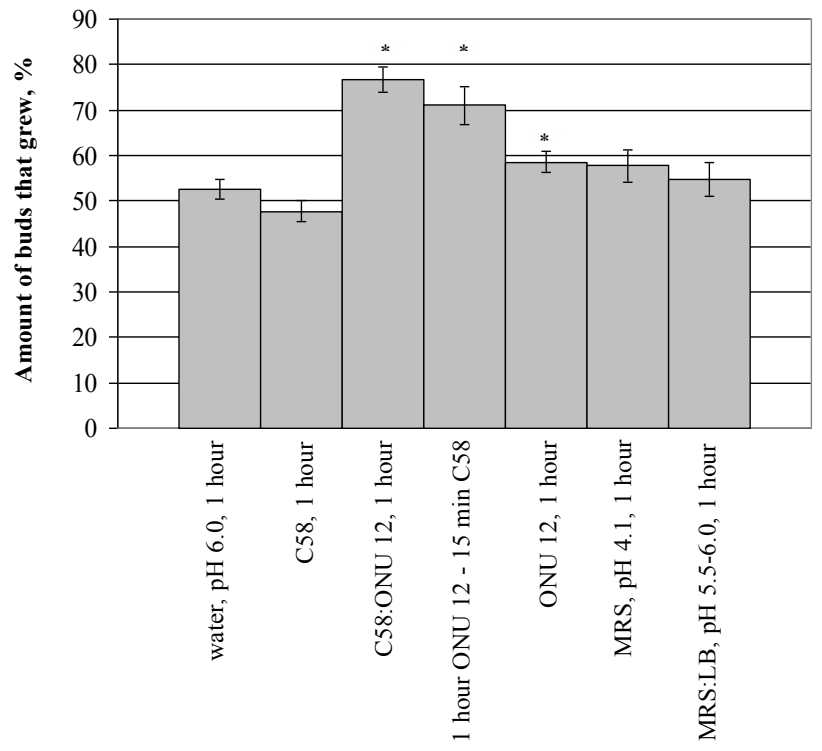

Figure 5: Effect of the treatments of grape cuttings with A. tumefaciens C58 and $L$. plantarum ONU 12 on amount of buds that grew (expressed as a mean $\pm \mathrm{SE})$ : * - significant differences between means after soaking in SDW and soaking in lactobacilli alone and in combinations of bacteria ( $p<0.05, t$ test)

of green shoots formed in grape cuttings treated with A. tumefaciens C58 and L. plantarum ONU 12 in different combinations didn't differ significantly from the control (data not shown).

PCR with DNA of bacteria isolated from the treated cuttings showed the presence of pathogenic agrobacteria in tissues of $87.2 \%$ of samples inoculated in positive controls (Table 4). After a treatment with a mixture "A. tumefaciens C58/L. plantarum ONU 12" the amount of infected cuttings decreased to $17.0 \%$. One-hour preliminary treatment with L. plantarum ONU 12 culture followed by a 15 min inoculation with A. tumefaciens C58 helped to decrease the amount of infected plants to $27.5 \%$ [52].

\section{Discussion}

Investigations of $\mathrm{LAB}$ use in plant protection against bacterial and fungal infections, for plant growth stimulation and for soil treatment have been largely described [1-3,5-9,53]. However, the possibility of crown gall biocontrol with LAB has not been evaluated yet. For the preliminary tests, we used the carrot disc model, what allowed to obtain rapid results and to carry out the simultaneous estimation of possibility of LAB strains to cause fermentation of plant tissues. It is mostly because of their fermentative activity and consecutive acidification of fermented media that LAB are used for food preservation [54]. For plant protection it was necessary to find strains with low fermentative activity not causing significant damage of wounded tissues.

Whereas in vitro tests have showed that the main inhibitory effect was based on low $\mathrm{pH}$, different strains of LAB with the same $\mathrm{pH}$ of overnight cultures still varied in levels of their antagonistic activities in vivo on carrot explants showing the presence of other factors involved in suppression of phytopathogens. Still on this stage of the experiment it is unclear what is the mechanism of such inhibition. The suppression of phytopathogens can occur on the next stage as well when bacteria of both species are applied on carrot disk surface and LAB compete for the nutrients, attachment sites and excrete metabolites such as organic acids (lactic acid) and oxygen peroxide, which affect negatively 


\begin{tabular}{|c|c|c|}
\hline \multirow{2}{*}{ Variant } & \multicolumn{2}{|c|}{ Amount of tested cuttings } \\
\cline { 2 - 3 } & Total & Infected (\%) \\
\hline A. tumefaciens C58 & 94 & 87.2 \\
\hline A. tumefaciens C58:L. plantarum ONU 12 & 88 & 17.0 \\
\hline $\begin{array}{c}\text { 1 hour L. plantarum ONU 12 then 15 min A. } \\
\text { tumefaciens C58 }\end{array}$ & 80 & 27.5 \\
\hline
\end{tabular}

Table 4: Presence of pathogenic agrobacteria in grapevine tissues after the experimental inoculation.

the survival of agrobacteria on plant surfaces. Different levels of antagonistic activity among strains of $L$. plantarum species described remain in agreement with the results of Visser et al. [1], Trias et al. [2], El-Mabrok et al. [5], who described the strain-specific effect of LAB against phytopathogens.

Strain L. plantarum ONU 12 with the highest antagonistic activity on carrot explants was also effective in suppressing crown gall on Kalanchoe daigremontiana and agrobacterial infection on grapevine cuttings. Depending on the method of inoculation, its suspension protected $100 \%$ of wounded tissues (via injections of the mixture " $A$. tumefaciens $\mathrm{C} 58 / \mathrm{L}$. plantarum ONU 12" or via soaking damaged roots and crowns in such a mixture), or decreased the number of galled plants by $98.5 \%$ (treatments of leaf scars with the mixture "A. tumefaciens C58/L. plantarum ONU 12") and by $72.7 \%$ in case of inoculation with agrobacteria followed by the treatment with LAB after $30 \mathrm{~min}$ interval.

Inoculation of grapevine with A. tumefaciens C58 culture reduced the number of viable cuttings, amount of buds that grew and mean length of green shoots from the cuttings that survived. A. tumefaciens in some cases can be a crown gall agent on grapevine, the same as $A$. vitis does $[15,16]$. Certain pathogenic strains originally isolated from grapevine as A. tumefaciens $\mathrm{FACH}$ was aggressive on kalanchoe but did not cause tumor formation on grapevine [51]. As for A. tumefaciens C58, its high tumorigenic activity on grapevines was reported by Holden et al. [54]. In our experiments, necroses instead of tumors were formed on all inoculated in the positive control grape cuttings. It was revealed by Bazzi et al. [27] that high concentrations of pathogenic A. vitis (approximately $10^{8} \mathrm{CFU} / \mathrm{mL}$ ) caused vast necroses of woody parenchyma instead of gall formation [55]. Plants with necrotic tissues exhibited poor growth and high mortality [28]. In the case of $A$. vitis, the necrogenic response of grape tissues can be explained by activity of polygalacturonase degrading cell walls [56] and other necrosis factors inducing inoculum-dependent damages on shoot explants and grape leaves [12]. A. tumefaciens C58 genome does not carry pehA gene responsible for polygalacturonase synthesis [51] and the mechanism of necrogenesis in case of $A$. tumefaciens is different from that induced by A. vitis [12]. Thus, strain A. tumefaciens A281 being super virulent on many plant species induced a necrogenic response (84\%) rather than gall formation on several grapevine cultivars and such necroses seemed to be cultivar specific and related to genes of Ti-plasmid. Exogenous auxin increased the level of necrogenesis and this implied that plant hormones influenced the process of necrogenesis limiting the tumor formation. Deng et al. [57] proposed the hypothesis that $A$. tumefaciensinduced necrotic response is a consequence of increased levels of auxin or precursors of auxin affecting grapevine cells. The greatest degree of necrogenesis was observed in case of inoculation of basal ends [58]. Treatments of basal ends of cuttings in our experiments resulted also in vast necroses and subsequent high mortality of grapevines.

Co-inoculation with agrobacteria and LAB removed completely the negative effect of phytopathogen on grapevines as it was shown by comparison of numbers of survived cuttings, amounts of buds and mean lengths of green shoots. If grapevine cuttings were inoculated simultaneously with A. tumefaciens C58 and L. plantarum ONU 12, amount of infected cuttings decreased by $81 \%$ whereas preliminary inoculation with L. plantarum ONU 12 reduced this number by $68.4 \%$ showing the effect of pre-treatments with LAB suspensions.

As for the number of buds that grew, higher stimulating effect of lactobacilli in a mixture with a pathogen was rather unexpected. Locke et al. [58] showed similar effect on buds distal to tumors caused by the attenuated culture of agrobacteria due to cytokinins produced by tumors (reviewed in Binns, [59]). In our study, tumors were not formed but the stimulation activity was observed.

Stimulating activity of the overnight culture of $L$. plantarum ONU 12 on number of buds that grew was not associated with the components of MRS medium but only with the substances synthesized by LAB. Indeed, soaking in MRS, $\mathrm{pH} 4.1$ as a negative control simulating the medium for lactobacilli with the lowest possible $\mathrm{pH}$ of the bacterial culture after appropriate time of incubation influenced negatively the grapes. The number of survived cuttings and mean length of green shoots decreased. Grapevine is not an acid tolerant plant, although vineyards with acid subsoils with $\mathrm{pH}$ lower than 5.0 are known (reviewed in Kirchhoff et al., [60]). Significant decrease in reduction of root and shoot biomass was observed in soils with $\mathrm{pH}$ below $4.5[61,62]$. Hence, it may be proposed that the positive effect of metabolites of L. plantarum ONU 12 compensated in executed experiments the unfavorable influence of low $\mathrm{pH}$ of overnight LAB culture.

Our previous investigations showed the stimulating effect of $L$. plantarum ONU 12 on development of tomato seedlings. In that case we used LAB cells washed from MRS with metabolites synthesized overnight and resuspended in SDW with final $\mathrm{pH}$ 5.0-5.2 [63]. Thus, the treatment with washed cells in case of tomato seeds and with overnight culture in MRS in case of grapevine cuttings had stimulating effect on test plants in both experiments.

Positive effects of treatments of the plants with lactobacilli under field [6] and laboratory conditions [63] has been described. Improving of root and shoot lenghts $[53,63]$, including plants on plots infested with Fusarium oxysporum [6] indicated the possibility of treatments with lactobacilli not only as antimicrobial agents but also as plant stimulating microorganisms.

Taking into account the marked antagonistic activity in vivo, $L$. plantarum ONU 12 can be proposed as a microorganism with the high potential for protection of plants against A. tumefaciens. However, experiments with more of other plant varieties and species in green house and under field conditions would be still needed for deeper evaluation of all potential of practical use of studied LAB.

\section{Acknowledgments}

The authors express their gratitude for support of this study by the Bilateral French-Ukrainian collaboration program "Dnipro" (2011-2012) granted by the Ministry of Foreign and European Affairs of France and the State Agency of Science, Innovations, and Information of Ukraine, and for support in frame of the programme "Science in Universities" NU3-2011 granted by the Ministry of Education, Science, Sport and Youth of Ukraine. Authors express their gratitude to Dr. Matheus de Sousa Barbosa, Dr. Sarah Migaw and Dr. Ganna Yamborko for kindly providing the strains E. faecium C8, E. durans 3y, L. plantarum ONU 87, ONU 206 and ONU 991.

\section{References}

1. Visser R, Holzapfel WH, Bezuidenhout JJ, Kotze JM (1986) Antagonism of lactic acid bacteria against phytopathogenic bacteria. Applied and Environmental Microbiology 52: 552-555. 
Citation: Limanska N, Korotaeva N, Biscola V, Ivanytsia T, Merlich A, et al. (2015) Study of the Potential Application of Lactic Acid Bacteria in the Control of Infection Caused by Agrobacterium tumefaciens. J Plant Pathol Microb 6: 292. doi:10.4172/2157-7471.1000292

2. Trias R, Bañeras L, Montesinos E, Badosa E (2008) Lactic acid bacteria from fresh fruit and vegetables as biocontrol agents of phytopathogenic bacteria and fungi. International Microbiology 11: 231-236.

3. Dalirsaber Jalali M, Khosro I, Ghasemi MF, Tabrizi SSKh (2012) Antagonism of Lactobacillus species against Xanthomonas campestris isolated from different plants. Journal of Applied Environmental and Biological Sciences 9: 480-484

4. Lwin M, Ranamukhaarachchi SL (2006) Development of biological control of Ralstonia solanacearum through antagonistic microbial populations. International Journal of Agriculture and Biology 8: 657- 660.

5. El-Mabrok ASW, Hassan Z, Mokhtar AM, Aween MM (2012) Efficacy of Lactobacillus plantarum C5 cells and their supernatant against Colletotrichum gloeosporioides on germination rate of chilli seeds. Research Journal of Biological Sciences 7: 159-164.

6. Hoda AH, Yomna AM, Shadia MA-A (2011) In vivo efficacy of lactic acid bacteria in biological control against Fusarium oxysporum for protection of tomato plant. Life Science Journal 8: 462-468

7. Xu J, Ran L, Yang B, Li Z (2002) Inhibition of Lactobacillus species on the germination of Aspergillus flavus spore. Wei Sheng Yan Jiu 31: 47-49.

8. El-Taher EM, El-Ghany ATM, Alawlaqi MM, Ashour MS (2012) Biosecurity for reducing ochratoxin A productivity and their impact on germination and ultrastructures of germinated wheat grains. Journal of Microbiology and Biotechnology and Food Sciences 2: 135-151.

9. Corsetti A, Gobbetti M, Rossi J, Damiani P (1998) Antimould activity of sourdough lactic acid bacteria: identification of a mixture of organic acids produced by Lactobacillus sanfrancisco CB1. Applied Microbiology Biotechnology 50: 253-256.

10. Wang H, Yan Y, Wang J, Zhang H, Qi W (2012) Production and characterization of antifungal compounds produced by Lactobacillus plantarum IMAU10014. PloS ONE. doi: 10.1371/journal.pone.0029452.

11. Young JM, Kuykendall LD, Martinez-Romero E, Kerr A, Sawada H (2001) A revision of Rhizobium Frank 1889, with an emended description of the genus, and the inclusion of all species of Agrobacterium Conn 1942 and Allorhizobium undicola de Lajude et al. 1998 as new combinations: Rhizobium radiobacter, $R$ rhizogenes, R. rubi, R. undicola and R. vitis. International Journal of Systematic and Evolutionary Microbiology 51: 89-103.

12. Burr TJ, Otten $L$ (1999) Crown gall of grape: biology and disease management Annual Review Phytopathology 37: 53-80.

13. Kersters K, De Ley J (1984) Genus III. Agrobacterium Conn: Bergey's Manual of Systematic Bacteriology. Vol. 1, Williams and Wilkins Co., Baltimore-London.

14. Ophel K, Kerr A (1990) Agrobacterium vitis sp. nov. for strains of Agrobacterium biovar 3 from grapevines. International Journal of Systematic and Evolutionary Microbiology 40: 236-241.

15. Süle S, Burr TJ (1998) The effect of resistance of rootstocks to crown gall (Agrobacterium spp.) on the susceptibility of scions in grapevine cultivars. Plant Pathology 47: 84-88.

16. Szegedi E, Bottka S, Mikulás J, Otten L, Süle S (2005) Characterization of Agrobacterium tumefaciens strains isolated from grapevine. Vitis 44: 49-54.

17. Chilton MD, Drummond MH, Merlo DJ, Sciaky D, Montoya AL, et al. (1977) Stable incorporation of plasmid DNA into higher plant cells: the molecular basis of crown gall tumorigenesis. Cell 11: 263-271.

18. Inzé D, Follin A, van Lijsebettens M, Simoens C, Genetello C, et al. (1984) Genetic analysis of the individual T-DNA genes of Agrobacterium tumefaciens: further evidence that two genes are involved in indole-3-acetic acid synthesis. Molecular and General Genetics 194: 265-274

19. Guyon P, Chilton MD, Petit A, Tempe J (1980) Agropine in «null-type» crown gall tumors: evidence for the generality of the opine concept. Proceedings of the National Academy of Sciences of the United States of America 77: 26932697.

20. Filo A, Sabbatini P, Sundin GW, Zabadal TJ, Safir GR, et al. (2013) Grapevine crown gall suppression using biological control and genetic engineering: a review of recent research. American Journal of Enology and Viticulture 64 $1-14$.

21. Kerr A (1972) Biological control of crown gall: seed inoculation. Journal of Applied Bacteriology 35: 493-497.

22. Vicedo B, Penyalver R, Asins MJ, Lopez MM (1993) Biological control of Agrobacterium tumefaciens, colonization, and pAgK84 transfer with Agrobacterium radiobacter K84 and the Tra- mutant strain K1026. Applied and Environmental Microbiology 59: 309-315.

23. Jones DA, Ryder MH, Clare BG, Farrand SK, Kerr A (1988) Construction of a Tra- deletion mutant of pAgK84 to safeguard the biological control of crown gall. Molecular and General Genetics 212: 207-214.

24. Junaid JM, Dar NA, Bhat TA, Bhat AH, Bhat MA (2013) Commercial biocontro agents and their mechanism of action in the management of plant pathogens. International Journal of Modern Plant \& Animal Sciences 1: 39-57.

25. Kerr A, Roberts WP (1976) Agrobacterium: correlations between and transfer of pathogenecity, octopine and nopaline metabolism and bacteriocin 84 sensitivity. Physiological Plant Pathology 9: 205-211.

26. Staphorst JL, van Zyl FGH, Strijdom BW, Groenewold ZE (1985) Agrocinproducing pathogenic and nonpathogenic biotype-3 strains of Agrobacterium tumefaciens active against biotype-3 pathogens. Current Microbiology 12: 45-52.

27. Burr TJ, Reid CL (1994) Biological control of grape crown gall with nontumorigenic Agrobacterium vitis strain F2/5. American Journal of Enology and Viticulture 45: 213-219.

28. Bazzi CM, Alexandrova E, Stefani F, Anaclerio F, Burr TJ (1999) Biological control of Agrobacterium vitis using non-tumorigenic agrobacteria. Vitis 38: 31-35.

29. Burr TJ, Reid CL, Tagliati E, Bazzi C, Süle S (1997) Biological control of grape crown gall by strain $\mathrm{F} 2 / 5$ is not associated with agrocin production or competition for attachment sites on grape cells. Phytopathology 87: 706-711.

30. Herlache TC, Zhang HS, Ried CL, Carle SA, Zheng D, et al. (2001) Mutations that affect Agrobacterium vitis-induced necrosis also alter its ability to cause a hypersensitivity response on tobacco. Phytopathology 91: 966-972.

31. Creasap JE, Reid CL, Giffinet MC, Aloni R, Ullrich C, et al. (2005) Effect of wound position, auxin, and Agrobacterium vitis strain F2/5 on wound healing and crown gall in grapevine. Phytopathology 95: 362-367.

32. Kaewnum S, Zheng D, Reid CL, Johnson KL, Gee JC et al. (2013) A hostspecific biological control of grape crown gall by Agrobacterium vitis strain F2/5: its regulation and population dynamics. Phytopathology 103: 427-435.

33. Liang ZH, Wang HM, Wang JH (2001) Preliminary study on effectiveness and the stability of E26 on controlling crown gall disease. Journal of China Agricultural University 6: 91-95.

34. Wang HM, Wang HX, Ng TB, Li JY (2003) Purification and characterization of an antibacterial compound produced by Agrobacterium vitis strain E26 with activity against $A$. tumefaciens. Plant Pathology 52: 134-139.

35. Yun LJ, Wang HM, Wang JH (2004) A bacteriocin with a broad spectrum activity produced by grapevine crown gall biocontrol strain E26. Scientia Agricultura Sinica 37: 1860-1865.

36. Chen XY, Xiang WN (1986) A strain of Agrobacterium radiobacter inhibits growth and gall formation by biotype III strains of A. tumefaciens from grapevine. Acta Microbiologica Sinica 26: 193-199.

37. Pu X-A, Goodman RN (1993) Tumour formation by Agrobacterium tumefaciens is suppressed by Agrobacterium radiobacter HLB-2 on grapevine plants American Journal of Enology and Viticulture 44: 249-254.

38. Kawaguchi A, Inoue K, Nasu H (2007) Biological control of grapevine crown gall by nonpathogenic Agrobacterium vitis VAR03-1. Journal of General Plant Pathology 73: 133-138.

39. Kawaguchi A, Inoue K, Ichinose Y (2008) Biological control of crown gall of grapevine, rose, and tomato by nonpathogenic Agrobacterium vitis strain VAR03-1. Phytopathology 98: 1218-1225.

40. Kawaguchi A, Inoue K (2012) New antagonistic strains of non-pathogenic Agrobacterium vitis to control grapevine crown gall. Journal of Phytopathology 160: 509-518.

41. Khmel IA, Sorokina TA, Lemanova NB, Lipasova VA, Metlitski OZ (1998) Biological control of crown gall in grapevine and raspberry by two Pseudomonas spp. with a wide spectrum of antagonistic activity. Biocontrol Science and Technology 8: 45-57.

42. Eastwell KC, Sholberg PL, Sayler RJ (2006) Characterizing potential bacterial biocontrol agents for suppression of Rhizobium vitis, causal agents of crown gall disease of grapevines. Crop protection 25: 1191-1200.

43. Bell CR, Dickie GA, Chan JWYF (1995) Variable response of bacteria isolated 
Citation: Limanska N, Korotaeva N, Biscola V, Ivanytsia T, Merlich A, et al. (2015) Study of the Potential Application of Lactic Acid Bacteria in the Control of Infection Caused by Agrobacterium tumefaciens. J Plant Pathol Microb 6: 292. doi:10.4172/2157-7471.1000292

from grapevine xylem to control grape crown gall disease in planta. American Journal of Enology and Viticulture 46: 499-508.

44. Chen F, Li JY, Guo YB, Wang JH, Wang HM (2009) Biological control of grapevine crown gall: purification and partial characterization of an antibacterial substance produced by Rahnella aquatilis strain HX2. European Journal Plant Pathology 124: 427-437.

45. Toklikishvili N, Dandurishvili N, Vainstein A, Tediashvili M, Giorgobiani N, et al. (2010) Inhibitory effect of ACC deaminase-producing bacteria on crown gall formation in tomato plants infected by Agrobacterium tumefaciens or A. vitis. Plant Pathology 59: 1023-1030.

46. Biondi E, Bini F, Anaclerio F, Bazzi C (2009) Effect of bioagents and resistance inducers on grapevine crown gall. Phytopathologia Mediterranea 48: 379-384.

47. de Man JC, Rogosa M, Sharpe ME (1960) A medium for the cultivation of lactobacilli. Journal of Applied Bacteriology 23: 130-135.

48. Bertani G (1951) Studies on lysogenesis. I. The mode of phage liberation by lysogenic Escherichia coli. Journal of Bacteriology 62: 293-300.

49. Ryder MH, Tate ME, Kerr A (1985) Virulence properties of strains of Agrobacterium on the apical and basal surfaces of carrot root disks. Plant Physiology 77: 215-221.

50. Batdorj B, Trinetta V, Dalgalarrondo M, Prévost H, Dousset X, et al. (2007) Isolation, taxonomic identification and hydrogen peroxide production by Lactobacillus delbrueckii subsp lactis T31, isolated from Mongolian yoghurt: inhibitory activity on food-borne pathogens. Journal of Applied Microbiology 103: 837-848.

51. Eastwell KC, Willis LG, Cavileer TD (1995) A rapid and sensitive method to detect Agrobacterium vitis in grapevine cuttings using the polymerase chain reaction. Plant Disease 79: 822-827.

52. Haas JH, Moore LW, Ream W, Manulis S (1995) Universal PCR primers for detection of phytopathogenic Agrobacterium strains. Applied and Environmental Microbiology 61: 2879-2884.
53. Higa T, Kinjo $S$ (1989) Effect of lactic acid fermentation bacteria on plant growth and soil humus formation. Proceedings of $1^{\text {st }}$ International Conference on Kyusei Nature Farming.

54. Daeschel MA, Fleming HP (1984) Selection of lactic acid bacteria for use in vegetable fermentations. Proceedings of the symposium "Selection parameters of microorganisms for use in the fermentation of plant foods and beverages".

55. Holden M, Krasatanova S, Xue B, Pang S, Sekiya M, et al. (2003) Genetic engineering of grape for resistance to crown gall. Acta Horticulturae 603: 481 484 .

56. Burr TJ, Bishop AL, Katz BH, Blanchart LM, Bazzi C (1987) A root specific decay of grapevine caused by Agrobacterium tumefaciens and A. radiobacter biovar 3. Phytopathology 77: 1474-1427.

57. Pu XA, Goodman RN (1992) Induction of necrogenesis by Agrobacterium tumefaciens on grape explants. Physiological and Molecular Plant Pathology 41: $241-254$

58. Deng W, Pu XA, Goodman RN, Gordon MP, Nester EW (1995) T-DNA genes responsible for inducing a necrotic response on grapevines. Molecular PlantMicrobe Interactions 8: 538-548.

59. Locke SB, Riker AJ, Duggar BM (1938) Growth substance and the development of crown gall. Journal of Agricultural Research 57: 21-39.

60. Binns AN (2008) A brief history of research on Agrobacterium tumefaciens: 1900-1980s: Agrobacterium: from biology to biotechnology. Springer, New York.

61. Kirchhof G, Blackwell J, Smart RE (1991) Growth of vineyard roots into segmentally ameliorated acidic subsoils. Plant and Soil 134: 121-126.

62. Bates TR, Dunst RM, Taft T, Vercant M (2002) The vegetative response of "Concord" grapevines to soil pH. Horticultural Science 37: 890-893.

63. Limanska N, Ivanytsia T, Basiul O, Krylova K, Biscola V, et al. (2013) Effect of Lactobacillus plantarum on germination and growth of tomato seedlings. Acta Physiologiae Plantarum 35: 1587-1595. 